\title{
Introduction
}

No man is satisfactorily dressed unless he has both coat and trousers; that does not mean that till he is sure of his coat he will be warmer without any trousers. In being asked to report on social insurance and allied services, I was not asked to say how employment should be maintained; I was not asked to design a complete suit - only the trousers. I have designed the trousers, that is to say, the scheme of social insurance. My advice is that with a free mind we can see about a coat as well (that is to maintenance of employment) and about other parts of our reconstruction wardrobe. (Beveridge, 1943, p. 139)

Pensions are one of the hottest discussion issues nowadays. This is the consequence of the conservative attack on the welfare state institutions that, in the case of pensions, finds an additional justification in the fears brought about by the ageing process of our societies. This book is a contribution to the present debate on pension reforms in the light of the existence of rival economic theories. In most of the book the discussion will be mainly theoretical, but empirical references will be episodically provided as examples for clarification and to illustrate the practical relevance of the analytical propositions. The last chapter speculates about the conceivable economic impact of the ongoing demographic developments interpreting some possible empirical scenarios in the light of rival economic approaches.

The dominant opinion is that we are facing a crisis of the public pension systems organized on an 'unfunded' pay-as-you-go $(P A Y G)$ basis. The occurring demographic shocks - more specifically, decreasing fertility rates and improved life expectancy and, more contingently, the retirement of the baby-boom generation - are often mentioned as the main cause of the crisis. In contradiction with this view, it will be shown that the problems with $P A Y G$ are essentially economic and not demographic, in spite of the dramatic nature of the latter. Demography is indeed used to give an aura of ineluctability to pension reforms aimed at dismantling $P A Y G$ schemes, which in turn are the most significant portion of the welfare state (Mullan, 2000). A first reform proposal, already adopted in some European countries, involves a stricter application of some principles of old-age private insurances to $P A Y G$. A second reform proposal attempted in some developing countries is the substitution, total or partial, of $P A Y G$ with a private capitalization or 
'fully-funded' ( $F F$ ) system (World Bank, 1994; OECD, 1998). The choice between the two schemes is not a question of political preferences, say public versus private management, but of economic evaluation of its effects on income distribution and growth. The main object of this book is to study the nature, process of creation, sustainability and alleged advantages of the two competing pension systems ( $P A Y G$ and $F F$ ) in the light of the existence of alternative economic theories of income distribution and growth. The first approach is the dominant neoclassical or marginalist theory; the second is what we shall define as the classical-Keynesian approach (or sometimes classical approach when referring to distribution theory only) erected on the contributions of the classical economists and Marx, of Keynes, Kalecki, Sraffa and many others. ${ }^{1}$ As we shall see, the conclusions reached by each of these two competing approaches with regard to the advantages of the two systems and to the causes of the alleged crises of $P A Y G$ differ radically. In particular, the second, less conventional, approach suggests that the sustainability of $P A Y G$ is of an economic and not a demographic nature, and that the adoption of an $F F$ scheme may prove abortive and, at the same time, harmful to employment and growth.

Although it is difficult in the field of economics - or political economy, to use the pre-Marshallian term - to disentangle the political preferences about income distribution from economic investigation, unprejudiced analysis should proceed independently of them. One main advantage of the classical approach is that the existence of conflicting social preferences are, so to speak, endogenized by the theory, but not because of the a priori preconceptions of the investigator, but as a constituent part of the economic approach. This is the result of the conflict view of income distribution that characterizes the Classical approach. ${ }^{2}$ Accordingly, on the one hand, economic choices are seen not as the outcome of some neutral economic criteria, but as the result of the political circumstances prevailing in the period under consideration; on the other hand, political considerations on income distribution are not an ex ante stance adopted by the scholar, who limits himself to the interpretation of a conflict written in the facts (that the theory helps to discern). A standard example of such an approach is the paper by Michael Kalecki (1943a) who provided an explanation of persistent unemployment in the presence of economic policy prescriptions capable, in principle, of abolishing it, based on the political concern of the dominant class about the social indiscipline brought about by full employment. In this view unemployment is seen as instrumental in keeping social conflict under control. A conflict view of distribution is also shared by the Power Resource Theory proposed by some Scandinavian scholars of the welfare state (see below Chapter 7). ${ }^{3}$ Directly relevant to this study is the conflict view of distribution present in two theoretical streams of studies on social 
gerontology known, respectively, as the political economy of ageing and moral political economy (Minkler and Estes, 1991). Both look at the relation between the concept of old age and capitalism, with a particular concern for class relationships, and for the evolving political and social nature of the notions of retirement and pensions. The classical-Keynesian approach to pensions pursued here is particularly open to a mutual fertilization with these approaches (Jackson, 1991).

The present period, dominated by the marginalization of critical theories, is not perhaps the most favourable for asserting the existence of competing economic approaches. Nevertheless, only three decades ago the neoclassical edifice was faced with a formidable challenge: the capital theory controversy. Of course, this controversy was preceded thirty years earlier by Keynes's challenge and, we shall argue, complemented it in some respect. The capital theory controversy was probably the most famous and passionate in the history of economic thought, not least because of its undoubted ideological relevance, but it was not vague in its object since it centred upon very precise analytical questions. More specifically it focused on the impossibility of measuring the productive factor 'capital' independently of distribution (a problem well known to the most rigorous early marginalists) and on the associated impossibility of deriving the downward sloping demand curves for the production factors. Sheshinski, a leading neoclassical economist, recalls:

When I came to MIT at the end of 1963, the factory producing with Solowian equipment was in high gear ... The world was watching and, yes, guns were roaring - mostly applauding salvos, but sometimes 'shooting to kill'. They were also times of polemics. Before the age of fax machines, notes and counterexamples were hurried across the Ocean. Bob or Paul would enter class with an airgram from Pasinetti or Garegnani or Robinson in hand, read their (tedious) numerical examples, and conjecture that they did not satisfy some basic assumptions. We would then rush home to invert $4 \times 4$ indecomposable inputoutput matrices and send off the next salvo across the ocean. (Sheshinski, 1990, p. 41)

Famously, referring to Samuelson's (1966) summing up of the controversy, Ferguson (1979, p. 269) admitted that 'Cambridge Criticism is valid' and that his belief in neoclassical theory was just 'a statement of faith', relieved solely by the hope that empirical research might, in the future, circumscribe the relevance of the criticism - as if logical faults could be remedied by empirical results! The same religious spirit was shared by Solow's definition of neoclassical distribution theory as a 'parable' (Solow, 1970, p. 1). Solowian aggregate growth theory was indeed the most obvious victim of the criticism. In the 1950s and 1960s neoclassical growth theory was actually an 
amateur field, whereas Keynesian literature dominated in macroeconomics although in the neoclassical-contaminated versions of Hicks-Modigliani and in growth theory in the Harrod-Domar version. Now, after almost two decades of monetarism, so called 'neo-Keynesianism' again dominates although it has changed in almost everything but name. Critical economists are treated with contempt either as stubborn fossils from too intensely ideological times fussing over irrelevant details or paradoxes, or as comparatively non-rigorous scholars, obsessed by an anti-capitalist bias. ${ }^{4}$ For the time being, it is not so much that the Sraffian criticism of neoclassical capital theory and the recovery of the classical approach did not deliver what they promised, as is sometimes argued, but that times have become less favourable. Few previously radical scholars have rejoined the ranks of the mainstream. Many of them took refuge in other non-mainstream areas such as institutional economics, methodology or evolutionary theory, that are less disturbing for neoclassical economics. ${ }^{5}$ Young students are nowadays less interested in critical theory, and perhaps those who are, are suspicious of economics. Nonetheless, the classical-Keynesian approach has slowly but steadily advanced, in particular by clarifying the relationship between the classical approach to distribution and the Keynesian-Kaleckian accumulation theory, as shown in Chapter 6. On their side, mainstream economists have never really answered the criticism of capital theory.

As observed above, a direct victim of the capital controversy is the neoclassical theory of economic growth. This theory plays a central role in the dominant view of the $F F$ scheme as favourable to accumulation and of $P A Y G$ as detrimental to it. By applying the classical approach to the question of pensions, we do not expect only to enrich the debate on pension reforms with a new perspective, but also to develop the critical approach itself from the point of view of distribution and of accumulation theory by including pensions in both aspects of the theory. In a significant number of cases, however, this book does not intend to deal with grand theory, but rather with the internal consistency of the proposals of pension reform. This is notably the case regarding the well-known problem of the transition from a $P A Y G$ scheme to an $F F$ scheme. In this case the effort will mainly be to clarify the question within the frame of traditional theory.

\section{STRATEGY OF THE BOOK}

The book is mainly devoted to the theoretical background of the debate on pension reforms. As a side effect, this debate will be a spring-board for a comparative assessment of the above-mentioned two alternative approaches to income distribution and growth. The originality of the book is precisely in 
opening new theoretical perspectives in the debate on pensions, which is dominated mainly by conventional theorizing. None the less, there is still a possibility that some readers, although interested in an alternative viewpoint on pension reforms, might be less attracted by the more general theoretical discussion. So, avoiding what perhaps would have been the most logical sequence, that is starting with a general comparison of the two alternative theoretical approaches here considered, classical-Keynesian and marginalist, the book will instead start directly with the debate on pension systems and reforms that will concern us in the first five chapters. It may be wise to do so also to show in vivo the sense in which the existence of alternative approaches in economic theory, that will be introduced as we proceed, can be illuminating in solving certain controversies regarding pensions. If these chapters succeed in arousing the reader's curiosity, s/he may then look at the wider economic controversies on distribution, employment and the welfare state, which are more systematically illustrated in the sixth and seventh chapters, and at the original sources cited there. I will return to the pension issue in the final chapter that explores the future of $P A Y G$ in the context of the possible economic effects of the ongoing demographic developments. Also in this case, non-orthodox thinking suggests directions different from those of conventional theory. ${ }^{6}$

As said, the spirit of the book is mainly theoretical. However, in order to support the analytical arguments and to guarantee a minimum interaction between theory and practice, I will occasionally provide applied references. In particular, the references will involve the US, where the theoretical and political debate on pensions is particularly lively, Italy, a country at the forefront of the European debate, and Latin America, a laboratory for mainstream pension reforms. Some global demographic trends are examine in the last chapter. The spirit of the book is, indeed, also to promote further empirical and historical research in non-orthodox directions.

In discussing pension reforms the strategy of the book is as follows. Chapters 1 and 2 focus on $P A Y G$, discussing its controversial nature and the reforms claiming to improve its sustainability. Chapters 3 and 4 focus on the $F F$ scheme, examining its nature and the proposals to replace $P A Y G$ with it. In these two chapters the discussion is conducted, at least in part, within a neoclassical framework. This may appear surprising in a book that aims at presenting a non-conventional approach to pensions. This procedure is adopted for the sake of the argument it reveals, in order to show up the inconsistencies and difficulties encountered in the conventional approach when proposing the substitution of $P A Y G$ with an $F F$ scheme. In this way, the classical-Keynesian criticism to conventional economics is employed, so to speak, to strike the final blow for the dominant reform proposals of substituting $P A Y G$ with the $F F$ schemes examined in the preceding sections. 
Chapter 5 examines the controversy over the 'trust fund' accumulated by the US Social Security. Chapters 6 and 7 show, in a more systematic way, the relevance of the non-conventional approach to the debate on pensions contributing, at the same time, to the integration of a welfare state theory in non-orthodox theory. More specifically, Chapter 6 presents the question of pensions in the perspective of Keynes's theory of effective demand, later reinforced by Sraffa's critique of traditional capital theory. Chapter 7 widens the perspective of the book by proposing a classical approach to the welfare state linking the non-conventional interpretations of $P A Y G$ examined in Chapters 1 and 2 to the classical theory of distribution. Finally, Chapter 8 discusses current and projected demographic developments. The ageing process is seen as a result of a process of stabilization of the world population. In the light of the classical and Kaleckian approach to the theory of distribution the main threat of the ageing process is found in the difficulty of capitalism to live with a shrinking industrial reserve army. Chapter 8 also poses the issue of the sustainability of $P A Y G$ as an economic question, and thus treatable by economic policies and appropriate changes in income distribution, and not as an ineluctable demographic quandary.

\section{OUTLINE OF THE BOOK}

Chapter 1 is concerned with the economic nature of $P A Y G$. It will begin by examining a number of contributions from the so-called political and moral economy of ageing that, historically and analytically, have investigated the origin of the notion of retirement and public pensions in capitalism. The scholars examined in this chapter suggest that the still-prevailing current view of the life course has emerged out of the necessities of capitalism concerning the renewal of the workforce and the regulation of social conflict - but was later seen by labour organizations as an opportunity to improve workers' life prospects, and that a continuous evolution has been witnessed, both in the actual organization and in the ideological justification of public intervention in support of old age. A central theme that emerges both from the historical accounts and the analytical debates is the likening of $P A Y G$ to private old-age insurances, which we shall call the 'insurance fiction'. The chapter examines this issue from various perspectives. In the main body of economic analysis the issue has been the subject of an important controversy initiated by a famous contribution by Samuelson (1958) followed by the subsequent criticism put forward by Lerner (1959). At the core of the dispute are the analytical and political pros and cons of the 'insurance fiction'. Samuelson interpreted $P A Y G$ as a device to transfer consumption over time as an alternative to capital accumulation. Lerner asserted the tax-transfer 
nature of that scheme, that is, as a device to distribute part of the social product period by period. The chapter places the controversy into perspective, showing the connection with the practical debates on $P A Y G$. We suggest that whereas Lerner's interpretation is the correct one, the 'insurance fiction' analytically synthesized by Samuelson has played various ideological roles in legitimating $P A Y G$ as a social and economic institution. In this capacity, the 'insurance fiction' will be considered as a 'social mythology', that is a tale that society has to tell itself to render some institutions or distributional settings more widely accepted. We shall later suggest in Chapter 7 that this approach, which links income distribution to the prevailing social conventions and norms, is akin to and nicely fits, the classical approach to distribution.

The debate on the merits of the 'insurance fiction' has found new vigour in recent years, since the 'insurance analogy' is the 'philosophy' behind the proposed reform of $P A Y G$ according to the principles of so-called 'notional defined contribution' (NDC) schemes. Chapter 2 discusses these reform proposals, which have found application in some countries, including Italy. The trade unions in some countries have endorsed this kind of reform, whereas in the past they had opposed the 'insurance fiction'. This confirms that any faction in conflict with regard to the definition of the amount of resources devoted to $P A Y G$ is ready to back the view of $P A Y G$ that best suits its purposes in the given historical circumstances. Whereas traditionally the 'insurance view' has been favoured by the conservative side, presently the most pro-market pension reformers would prefer to see $P A Y G$ dismantled or reduced to a safety net - and substituted with robust $F F$ schemes, while in some countries the trade unions have resorted to the insurance fiction to defend the public scheme. The NDC reforms, tried out in Italy, Sweden and elsewhere, are said: $(i)$ to introduce greater fairness in the calculation of pensions in favour of flat career workers, and (ii) to assure the financial sustainability of $P A Y G$ in view of the ageing process. Although (ii) cannot but imply cuts in the pension benefits, in view of $(i)$ they are said to hit steep career workers relatively more heavily. Moreover, the cuts will induce later retirement in order to safeguard retirement income. Given the fall in the labour supply from the younger age groups expected in the next two or three decades, later retirement would not displace the job opportunities for these generations, while increasing the demand for the labour supply from mature workers. Conventional economists have criticized the $N D C$ scheme as an inadequate substitute for a more radical reform aimed at creating $F F$ schemes, but this reform is not well founded, as shown in Chapters 3 and 4. The projections regarding Italy show that the $N D C$ reform is capable of stabilizing $P A Y G$ spending on GDP, at least in the long term. The open question is the ability of this ingenious reform, which focuses on financial 
sustainability only, to assure a decent standard of living for the future older generations.

The next three chapters explore and critique the most radical reform proposals. Chapter 3 explains the marginalist roots of the dominant view of the $F F$ scheme. In particular, the conventional notion of capital stock as a fund of consumption goods whose consumption is transferred into the future coincides with the conventional view of the $F F$ scheme as a device to postpone consumption from the active age into retirement. The solution of the old-age problem through an $F F$ scheme implies, therefore, that there is an increase in 'foresight' saving. Temporarily leaving aside Keynes's 'saving paradox', which is examined in Chapter 4, Chapter 3 discusses whether the creation of an $F F$ scheme is necessarily associated with a higher gross saving rate (and is not for instance a mere transfer of existing voluntary 'foresight' saving to a mandatory scheme) and, conversely, whether the introduction of a $P A Y G$ scheme necessarily leads to a fall in the saving rate. The alleged advantages of an $F F$ scheme in coping with the forthcoming demographic changes are examined next. This is important in order to evaluate the criticism raised by some opponents of $F F$ reform that, after all, the two competing schemes, $P A Y G$ and $F F$, are on the same footing with respect to the foreseen demographic shocks. Chapter 6 will later illustrate the standard view of the role played by foreign investment and 'endogenous growth' in preserving the profitability of an $F F$ scheme in the long run. An appendix will provide a simple formalization of the standard view of the capitalization scheme.

Chapter 4 discusses the 'transition problem' related to the transition from $P A Y G$ to $F F$ schemes. In view of the arguments presented in the preceding chapter, according to the conventional theory, the test of a successful transition from $P A Y G$ to an $F F$ scheme is the obtaining of a higher saving rate from full-employment income. Arguing, for the sake of analytical convenience, from within a conventional framework, it is shown that, given the existing commitments to pay current PAYG pensions, the possibility of a painless transition to capitalization simply does not exist. The passage to capitalization is only possible if somebody, be it current pensioners or workers, cuts their consumption. A reform proposal repeatedly advanced in the past is based on the diversion of $P A Y G$ contributions to private pension funds $(P F \mathrm{~s})$, while at the same time the state finances the current pension benefits by issuing public debt. It is shown that this kind of reform consists, prima facie, of a privatization of $P A Y G$, but not of a creation of a genuine $F F$ scheme. In this context it is briefly discussed how, reasoning in conventional terms, the famous Chilean reform circumnavigated these difficulties. I also suggest a non-conventional interpretation of the alleged good Chilean economic performance in the years of the reform. The chapter then examines 
the ancillary arguments usually put forward to justify the privatization of $P A Y G$. In particular, the World Bank admits that, although this kind of reform fails to create a genuine $F F$ scheme, by increasing the public debt it nonetheless may alarm public opinion about the costs of $P A Y G$ and pave the way to more radical reforms. We shall define this strategy, together with the Italian economist Federico Caffè, as a 'strategy of economic alarmism'. Two appendixes will also examine in detail the ambiguities and false promises that surround the transition plans proposed respectively by the World Bank (Holzmann, 1998) and by Martin Feldstein and his associates (Feldstein and Liebman, 2001). The final part of the chapter shows that even if the reform is capable of making the cut in the consumption of some social group politically digestible in order to raise the saving supply necessary to create an FF scheme, a second formidable obstacle apparently interferes in the transition. This is the weakness, both theoretical and empirical, of the conventional causal relation between saving and investment pointed out, from different but complementary perspectives by Keynes, Kalecki and Sraffa. Indeed, according to the classical-Keynesian approach the attempt to raise the propensity to save will lead to a fall in current output. As a result the pensions reform would, on the one hand, fail to increase aggregate saving and capital accumulation and, on the other hand, undermine the financial sources of $P A Y G$. A paradoxical result pointed out by Steindl is that $P A Y G$ 's deficits that result form the $F F$ reform will be financed by the newly created $P F$ s (that are, however, in this respect unfunded).

Chapter 5 examines the US controversy over the Social Security 'trust fund' $(S S T F)$. It is shown that, according to neoclassical theory, the $S S T F$ has a substantial meaning as a safety net in view of the alleged pending problems of $P A Y G$, but, according to more Keynesian principles, it does not play this function. Moreover, the establishment of a $S S T F$ will have deflationary effects on the economy.

Chapters 3, 4 and 5 showed that a reform aimed to create an FF pension scheme (based on the accumulation of real assets), even if successful at raising the marginal propensity to save (which should not be taken for granted), would fail since, according to Keynes's and Sraffa's criticism, it does not follow that the larger potential saving supply is necessarily translated into an increased amount of investment (more precisely in a higher per capita capital endowment). Chapter 6 extends the positive and critical implications of the classical-Keynesian approach for pension theory. After having illustrated the convergence of the theory of effective demand with the Sraffian criticism of neoclassical capital theory, we apply the nonconventional approach to the question of pensions and single out the nature of autonomous expenditure of $P A Y G$ 's transfers in the theory of effective demand. A more sympathetic view of a fully-funded pension reform is 
expressed by Michl and Foley (2004). Their support of transitional reform towards such scheme by basing it on a 'classical growth model' does not appear analytically robust since it lacks any plausible savings-based explanation of accumulation (alternative to the neoclassical one that, after the capital controversy, has to be rejected). This chapter will finally consider the relationship between pensions reform and the international capital movement in a conventional and non-orthodox perspective: the criticism of neoclassical capital theory and the theory of effective demand also dispose of the conventional idea that a higher saving supply from the northern countries will naturally flow to the capital-poor southern countries stimulating investment there. In this light, it is surprising to hear from less mainstreamoriented economists that if a country opts for pension funds, the risk is that savings are 'exported' instead of being invested at home. The risk is just deflation at home.

Chapter 7 links the conventional nature of $P A Y G$ 's regulations to the classical theory of distribution. This is characterized by the non-mechanical nature of the determination of income distribution, so that extensive space is given in it to the results of the conflict between social classes and to the social norms and conventions influenced by this conflict that, in a given historical context, define the degree and rights of accession to the social output by competing social groups. Taking advantage of some work done in this direction by Ian Gough (1979) and other authors in the 1970s, who were influenced by Sraffa's contribution, but also of other schools of the welfare state such as the Scandinavian 'power resource theory', the classical approach is extended to the interpretation of the welfare state. This interpretation is then compared to the conventional analysis provided by neoclassical welfare economics. In this framework state involvement is seen as an ex post intervention justified by the existence of market failures. By contrast, the classical approach is quite receptive to the view of the state as an ex ante regulator of class tension and the field of political conflict over the destination of the resources under its potential control. In this regard, a number of scholars have proposed the notion of a 'social wage' to integrate the direct wage so as to include the provision of welfare goods and services by the state. According to the classical approach both the direct and indirect parts of the wage rate include consuetudinary components. PAYG pensions, as they have developed in the social consciousness over the last century, can be seen as a part of the social wage as a consuetudinary expectation of support over the period of retirement. Retirement itself has also come to be considered as a part of life to be spent outside the labour market in advance of physical decline. The popular interpretation of public pensions as an acquired right to a 'deferred wage', common in many countries, in itself a concept devoid of any standard economic content (in National Accounts 
wages are a current flow of income), nevertheless encapsulates the consuetudinary social meaning of public pensions, and as such it acquires an analytical content.

The concluding Chapter 8 explores some possible implications of an ageing society and of $P A Y G$ within it. As the result of the retirement of the baby-boom generation and, more persistently, of the combination of lower fertility rates and higher longevity, developed and also intermediate economies are facing a process of ageing. The conventional wisdom is that a forthcoming labour scarcity plus the ageing process will place these economies under an intolerable stress. The chapter distinguishes between the consequences of ageing: $(i)$ on the labour market and (ii) on the economic viability of $P A Y G$. It begins by presenting some demographic scenarios, in order to assess the impact of the demographic developments on the level of the working-age population, which is the potential labour supply, and on the proportion of old-age population over the population in working-age, which affects the economic cost of ageing. Clearly, the economic impact of ageing cannot be evaluated by mere demographic indicators. We must also look, for instance, at the evolution of participation levels and of migration flows. The chapter points out the limitations of migration as a compensating factor for ageing. It turns next to the mainstream and non-conventional approaches to the labour market, welfare and distribution. For the neoclassical economists, a smaller labour supply would be reflected in a lower level of employment and higher wages. In practice conventional economists are worried about two problems. On the one hand, a situation of labour shortage might lead to greater labour bargaining power. On the other hand, the ageing process is associated with lower output levels that would put the sustainability of $P A Y G$ at risk. In the light of a classical-Kaleckian approach the consequences of a shrinking labour population are best considered with regard to the size of the industrial reserve army, whilst a larger share of output going to retired labour has no mechanical negative consequences on economic growth. The problem that emerges is the political opposition to a possible change in income distribution in favour of active and retired labour due to diminished competition in the labour market. The dominant classes, in particular in Europe, may react with stagnationist policies aimed at reconstituting the industrial reserve army.

The conclusions re-examine the main contents of the book, linking them together with the related theoretical and policy implications. 


\section{A NOTE ON TERMINOLOGY}

There is some terminological confusion in the literature that can also conceal substantial problems of interpretation. This section presents the classification used in this book, comparing it with some of the definitions found in the literature.

To begin with, pension systems will be subdivided into 'fully-funded' and 'unfunded' according to whether the expected benefits are, respectively, matched or not by an actuarially equal amount of real reserves. By real reserves we mean private financial assets (bonds and equities) representative of real capital.

What $P A Y G$ consists of is generally agreed upon. $P A Y G$ is an example of an unfunded scheme. Feldstein and Liebman (2001, p. 4), for instance, define it as an 'unfunded' pension scheme in so far as it does not entail the accumulation of financial assets as a reserve. According to National Accounts $P A Y G$ is a transfer of income from income earners to elderly nonincome earners. Some more subtle interpretative questions regarding the conceptualization of this transfer are discussed in Chapters 1 and 2.

If $P A Y G$ were accompanied by the accumulation of financial reserves, according to Feldstein and Liebman (ibid.) it would become "partially funded'. The economic content of this 'partial funding', whether it is just a 'notional funding' that does not substantially change the 'unfunded' nature of $P A Y G$, or whether it changes it, is a subtle point that is discussed in Chapter 5.

Orszag and Stiglitz (2001, pp. 18-19), and with some differences Geanakoplos et al. (1998, p. 3 and passim), distinguish between 'privatization' and 'prefunding'. By privatization they imply 'the replacing of a public run pension system with a privately managed one'; and by 'prefunding' the accumulation of 'assets against future pension payments'. Orszag and Stiglitz (2001, pp. 18-19) then differentiate between 'narrow' and 'broad prefunding'. By narrow prefunding these authors mean a system, in principle not necessarily public, that finances current benefits by issuing recognition bonds bought by the contributors. Although the participants in the scheme accumulate a reserve of financial assets, these are virtual and not real reserves: the plan will be solvent in the future, when the buyers of the recognition bonds return them in exchange for pension benefits, only as long as it is able to issue a sufficient amount of new recognition bonds in order to meet the present value of the past promises. In other words, a narrowly prefunded scheme is not, prima facie, different from a tax-financed pension scheme. So 'narrow prefunding' should be considered an unfunded scheme on the same footing as PAYG. Broad prefunding would instead imply the existence of 'real reserves' consisting of financial assets representative of 
real capital. This scheme is not necessarily privately managed. Broad prefunding corresponds to what we shall define as an $F F$ scheme and Feldstein just as funded programmes. 'Unfunded' and $F F$ schemes are of course the two extreme types. We may of course also have 'diversified' funds that, for instance, possess both notional and real reserves. Chapter 3 will consider whether these 'real reserves' assure the solvency of an FF scheme.

Summing up, Orszag and Stiglitz (2001) and Geanakoplos et al. (1998), make two important distinctions:

(i) They point out that pay-as-you-go, on the one hand, and broad prefunded policies (corresponding to our FF schemes and to Feldstein's funded systems), on the other, do not coincide respectively with public and private managed schemes; this suggests that the privatization of a pension scheme does not coincide with a transition to an $F F$ system. So, although pension reforms are typically identified with 'privatization' of public schemes, it is in principle possible to reform public $P A Y G$ pensions (as has actually been done) merely by leaving their management to private firms. Symmetrically, it is possible for public social security to use payroll taxes to invest in the stock market.

(ii) They distinguish between a genuine broad prefunded (our $F F$ ) scheme, associated with real reserves consisting of private assets representative of the capital stock, and a narrow prefunded scheme, in which there is an accumulation of financial assets, not representative of real capital. In Chapter 4 we shall see cases in which the privatization of $P A Y G$ leads solely to a narrow prefunded scheme.

Figure I.1 maps the possible combinations of pension systems according to their management (private or public) and of the content of the reserves they possess (none or government bonds; private assets representative of real capital assets). The figure suggests the chapter in which each specific system

\begin{tabular}{|l|l|ll|}
\hline \multicolumn{1}{|c|}{} & \multicolumn{2}{c|}{ Public } & \multicolumn{1}{c|}{ Private } \\
\cline { 2 - 4 } \multicolumn{1}{l|}{$\begin{array}{l}\text { Financial } \\
\text { reserves }\end{array}$} & $\begin{array}{l}\text { None or gov. bonds } \\
\text { (unfunded) }\end{array}$ & $\begin{array}{l}\text { PAYG } \\
\text { (Chapters 1 and 2) }\end{array}$ & $\begin{array}{l}\text { Narrowly funded } \\
\text { pension funds } \\
\text { (Chapter 4) }\end{array}$ \\
& $\begin{array}{l}\text { Real assets } \\
\text { (fully-funded })\end{array}$ & $\begin{array}{l}\text { Fully funded } \\
\text { trust funds } \\
\text { (Chapter 5) }\end{array}$ & $\begin{array}{l}\text { Fully funded } \\
\text { pension funds } \\
\text { (Chapter 3) }\end{array}$ \\
\cline { 3 - 4 } & &
\end{tabular}

Figure I.1 Classification of pension systems 
is dealt with. It may be said that the most radical reformers of the prevailing public $P A Y G$ systems would like to shift from northwest to southeast. Less radical reformers would perhaps like to move from northwest to southwest, with public 'trust funds' accumulating real capital assets. Chapters 3, 4 and 5 will try to assess the value of these attempts. I shall suggest that these reforms will lead northeast. Finally, moderate reformers would simply change the operating principles of $P A Y G$, not moving, therefore, from northwest. Also this kind of reform, however, has significant consequences, appraised in Chapters 1 and 2.

\section{NOTES}

1. These terms are preferred to the more common and narrower definitions of 'neoRicardians'. 'Marginalism' is favoured to define the dominant approach, although the more popular, but misleading, term 'neoclassical', which conveys a false idea of continuity between marginalism and the classical economists, will also be used.

2. Social choices about income distribution intrude indeed also into the marginalist approach after the failure of welfare economics to explain state intervention (see Chapter 7 below).

3. Gunnar Myrdal introduced his famous 'value judgements' in political economy in connection with the existence of conflicting interests in society that unavoidably condition the observer: 'Valuations are thus necessarily involved already at the stage when we observe facts and carry out theoretical analysis, and not only at the stage when we draw political inferences from facts and valuations. I have therefore arrived at the belief in the necessity of working always, from the beginning to the end, with explicit value premises. The value premises cannot be established arbitrarily: they must be relevant and significant for the society in which we live. To begin with, they must be made concrete in terms of economic interests actually pursued by groups of people, and of real human attitudes to social progress. Under no circumstances should the value premises in realistic research be represented by the sort of general and abstract principles of which the economists in our great tradition of natural law and utilitarianism avail themselves to bridge the gulf between objective science and politics' (1953, pp. vii-viii). Although the term 'value premises' is perhaps unsatisfactory since it reminds one of moral premises, much of the polemic of Myrdal is indeed against the 'barrage' of a priori 'categorical principles and basic concepts', in particular the 'harmony of interests' that characterizes conventional economics (ibid., pp. 192-93). Those premises should be proved 'on a factual basis for analysis'. And, according to Myrdal, the factual analysis suggests that conflict and not harmony of interests is the dominant fact: "If there is reason to believe that in a particular case interests are identical, this would have to be ascertained and proved. As a major premise, it should not be concealed by an a priori principle or a basic concept. The political conclusions are valid only in so far as this premise has been established as a factual basis for analysis. It is certainly not self-evident. But in most questions of economic policy there are conflicts of interests. This in fact should not be concealed by obscure talk of a priori principles. In those cases neither an economist nor anybody else can offer a "socially" or "economically correct" solution. No service is rendered to a rational conduct of politics by misusing scientific method for attempts to conceal conflicts' (ibid., p. 193). So Myrdal introduces the distributional conflict by appealing to the facts - not as an a priori prejudice - and on the 
same base the harmony of interests is repelled. Notably, he presented 'Ricardo's distribution theory' as 'hardly conducive to a justification of the doctrine of harmony' (ibid., p. 195). With these qualifications, Myrdal's view is not far from the unprejudiced approach to the investigation of facts (that is, not barred by a priori views) that Sraffian economists tend to attribute to the Classical economists.

4. It should be said that the dean of neoclassical economists, Paul Samuelson, has continued to debate with Sraffian economists (see Samuelson, 2000 and the long list of references provided by Garegnani, 2000). Updated sources about the capital controversy include Petri (2004) and Hahn and Petri (2003).

5. All these schools accuse neoclassical economics of not being in touch with the real world. This critique is sometimes also extended to the Sraffian approach. This criticism is partially misleading. This book shows, on the one hand, the relevance of both approaches for the analysis of a very practical question, pension reforms. On the other hand, it also shows the openness of the classical approach to history and institutions.

6. I should confess that when I started to write this book I tended to dismiss the demographic developments as overstated in order to attack public pensions. While I still believe that this interpretation is fundamentally correct, a closer inspection of the forthcoming population scenarios has revealed to me the importance of those changes. The last chapter of the book is my initial attempt at dealing with those developments in a non-conventional perspective.

7. As lucidly observed in an OECD publication: "The world "private" may be no more appropriate for a scheme with compulsory contributions at rates set by the government into funds managed by private companies but where the majority of the assets must be held in government debt, than for a compulsory state-run scheme where contributions are held in a fund invested largely in equity markets' (Kohl and O'Brien, 1998, p. 13). 